\title{
Vital Memories: movements in and between affect, ethics and self.
}

Steven D. Brown, University of Leicester

Paula Reavey, London South Bank University

\begin{abstract}
The focus on practice of remembering has been highly productive for memory studies, but it creates difficulties in understanding personal commitment to particular versions of the past. Autobiographical memories of difficult and distressing past episodes - or 'vital memories' require extensive and ongoing management. We describe the issues that arise when vital memories are expressed across a range of specific interactional contexts. Seven themes autobiography, agency, forgetting, ethics, affect, space, and institutional practices - are discussed. Each theme draws out a particular facet of the relationship between the content and contexts of vital memories and demonstrates that whilst vital memories frame problematic experiences, they remain essential for those who express them.
\end{abstract}

Keywords: Remembering practices; autobiographical memory; agency; ethics of memory; social remembering; organizational memory studies

\section{Introduction}

One of the great accomplishments of the highly varied traditions and bodies of work brought together within memory studies has been to recognise that the enormous significance of the forms and modalities through which remembering. There is a real difference between the work that goes on around, say, a formal commemorative act performed at a monument and comments left on a memorial Facebook page. Similarly a knotted handkerchief appears to function in a different way to a World Trade Centre snow globe (see Sturken, 2008). All of these examples constitute instances of 'memory', but hardly anyone within the field would judge them to be in any sense equivalent. This focus on practices of remembering has the additional benefit of displacing the troublesome debate around what memory 'really is' and over which disciplines ought to be responsible for clarifying and policing terminological, conceptual and methodological confusion (see Brown, 2008).

But the emphasis on social and cultural practices has created some difficulties in understanding the degree to which persons commit themselves to particular versions of the past (see Radstone, 2008). Clearly not all memories carry the same significance - recollecting the first time you saw clouds from an airplane window is of a different order from the memory of the last time you heard your mother's voice. Psychologists use the term 'autobiographical memories' (see Bernsten and Rubin, 2012 for a recent overview) to refer to recollection of episodes which are taken to have personal significance. Research on autobiographical memory emphasises that the valence and importance of recollected events changes over time, as a function of our current sense of self (Conway and Pleydell-Pearce, 2000). A memory of a disappointing night at a friend's party can, over time, come to be remembered as the beginning of that very dark time in my life. And may indeed come to take on some other significance as our life changes direction again. 
There are, however, certain kinds of memories that present considerably greater difficulties in

both accommodating into daily life and in reconstructing in alternative ways. For example, remembering episodes of childhood sexual abuse (CSA) (see Haaken and Reavey, 2009), or of being caught up in violent events such the 2005 London Bombings (see Allen and Brown, 2011). Autobiographical memories of this nature do not tend to waver in terms of their emotional power or personal significance. That is not to say that they are always remembered in the same way or that they are permanently corrosive of meaningful personal identity (as the literary uses of the trauma concept sometimes suggest). But rather, such memories will inevitably become enduring features of a personal past that will never cease to be relevant and requiring of management in the present.

Our ongoing research is concerned with particular kinds of autobiographical memories amongst so-called 'vulnerable' groups (see Brown and Reavey, 2014). These include survivors of child sexual abuse, adopted children and their families, forensic mental health service users, elderly persons in care home settings. With each group, we have learned of the importance of a particular class of memories. These are recollected episodes that are difficult and painful, which are sometimes contested, and that have enormous significance for a current and past sense of self. These are not memories that one can simply choose to remember or completely forget. They are instead memories that require considerable and ongoing work, which endures, perhaps, over the course of one's entire life. Furthermore, such memories are thoroughly interdependent with past and ongoing relationships to significant others. We use the term 'vital memories' to refer to this class of memories to indicate that these recollected events are crucial to a sense of self to such a degree that they can come to appear as a defining feature of a life.

In this paper we offer a series of themes that we think elucidate this particular class of memories. The seven themes we discuss - autobiography, agency, forgetting, ethics, affect, space, institutional practices - are neither definitive nor solely applicable to vital memories. Indeed our choice of a seven-part list follows the numerological trend in memory studies (see Connerton, 2008; Schacter, 2003). But the themes themselves are not arbitrary. They allow us to point to highly specific relationships between the content of these memories and particular interactional contexts (e.g. telling personal histories, accounting for past 'choices', public 'witnessing').

\section{Autobiography}

Middleton and Edwards' (1990) Collective Remembering collection was enormously significant for psychology in its introduction of a genuinely social approach to remembering that concentrated on the interactional processes involved in making some aspect of a personal past relevant in the present. This 'social remembering' approach demonstrated that collective remembering could be treated as the joint accomplishment of persons and which further served a range of interactional purposes, such as establishing membership, making attributions of blame, managing personal accountability, or constructing some future significance for the current interaction (see also Edwards and Potter, 1992; Edwards, Potter and Middleton, 1992). However, this approach arguably valorised the interactional dimension over the equally important task of constructing an ongoing sense of personal continuity and discontinuity. What we recall with others does not remain bounded by the present interaction, but has a degree of ongoing relevance for how we turn around on our personal history. 
Martin Conway's (1990) conception of 'autobiographical memory' is an important corrective

because of the central place it accords to the self-memory relationship. Our current sense of who and what we are is both the product of remembering and, reflexively, drives the accessibility of particular experiences which constitute recollections (i.e. we tend to recollect past event that are congruent with a present image of self) (Conway and Pleydell-Pearce, 2000). However, there are some difficulties with the model of autobiographical memory when it applied to 'vital memories'. Leaving aside the distraction of the philosophical headaches of combining cognitive and social epistemologies, the autobiographical memory model suggests that it is the role of a bundle of cognitive processes known as the 'working self' to access and retrieve memories. However, a common feature of all the groups we have worked with is that vital memories tend to be interdependent with the memories of others. For example, Elena Bendien's work on elderly visitors to a reminiscence museum in the Netherlands, showed the complex ways in which remembering was co-produced through and interaction between the visitors (often accompanied by adult children), material artefacts (such as old domestic appliances, tools or furniture) and the space itself (which was designed to replicate rooms in Dutch houses from the first half of the twentieth century) (see Bendien, 2012; Bendien, Brown and Reavey, 2011). Moreover, work in the autobiographical memory tradition tends to focus on events that fit neatly into cultural scripts of development (e.g. first love, marriage, first job, entry into university). By definition, vital memories, such as early experiences of a violent and/or traumatic nature, are based on experiences that deviate from or sit awkwardly within these cultural scripts (Conway and Jobson, 2012). Whilst this does not mean that they somehow stand outside other forms of experience, it does indicate that the work which goes on around these recollections is likely to be qualitatively and quantitatively distinct from that which occurs around other kinds of experiences.

\section{Agency}

Discussions of agency in relation to memory tend to treat agency as something that we fully possess or have in some way lost. In the literature on child sexual abuse, for example, the 'damage' incurred as a result of sexual abuse tends to negate version of children's and women's agency, in favour of totalising narratives of damage, unconscious repetition of the trauma and the necessity of subsequent therapeutic repair (Haaken, 1999; O’Dell, 2003; Reavey, 2003; Reavey, 2010). Agency is then seen to emerge as the result of having contained an unruly past, as with the neo-Freudian notion of 'working through' trauma. In his study of Veteran's Administration patients being treated for Post-Traumatic Stress Disorder (PTSD) on a psychiatric ward, Allan Young (1995) shows that linking current agency to a working through of trauma creates a different and complex relationship to personal history that he calls 'traumatic time'. The experience of this time is characterised by a continuous deferral of a perpetually justout-of-reach agency. The problem, as we see it, comes from treating agency as something we have or don't have. It would perhaps be better to think of the relationship between agency and memory using Bartlett's (1932) notion of 'turning on one's schema'. Bartlett coined this enigmatic phrase to describe how we may reflect upon the organization of our past experiences, and in so doing interrupt or create pauses in how memory informs our current activities (see Wagoner, 2014). For example, persons who have strong connections to the 2005 London Bombings typical spend considerable time reflecting on both what they remember and the ways 
in which they and others ought to remember this event in the future (see Allen and Brown,

2011). In this way, agency expands or dilates according to our capacity for such 'turning around'.

To reflect on the past does not mean that the past is put in some clear order, nor does is it necessarily expressed as a kind of autonomy or freedom in relation to our personal history. For example, survivors of child sexual abuse may routinely reflect on episodes of abuse, and may derive complex and contradictory feelings about their abuser and their own involvement in what happened. This may include struggles to determine whether there was some element of 'choice' on their part, along with attributions about the motivations of the abuser (Reavey and Warner, 2003; Reavey and Brown, 2006; Reavey, 2010). In some therapeutic practices (such as those studied by Young), this kind of ambivalence would be seen as an obstacle to achieving some kind of settlement with the past - to 'moving on'. But ambivalence may also be seen, in certain circumstances, as a powerful resource. By refusing to fix clear intentions and definitions of what happened, a space is opened up between past and present that can be productive because it allows difficult questions of one's moral character and personal capacities to be reformulated. At the heart of agency, therefore, has to be an understanding of the deep ambivalence individuals can feel about the actions performed in the past.

\section{Forgetting}

There are a number of detailed historical analyses of the changing ways in which memory has been conceived in Western culture and of the shifts in corresponding memory practices (see Yates, 1966; Matsuda, 1996; Draaisma, 2000). But forgetting also has a history. As Harald Weinrich (2004) shows in his literary-philosophical treatment, there are a great many classical sources, from Cicero to Nietzsche, that promote the practice of 'active forgetting' as providing salvation from a fixation on the past. This is typically accomplished through a displacement or deferral the past, such that a space to act in the present is opened up, rather than by outright disposal. The risk remains, however, that at a cultural level, such practices result in the kind of impermanence and self-conscious erasure of the past in the name of the 'new' that Connerton $(2008$; 2009) sees as characterising modernity. Connerton's analysis is concerned with political and cultural economy, rather than particular memorial practices. In a published response, Singer \& Conway (2008) suggests that the cognitive-experimental distinction between the 'availability' and 'accessibility' of memories provides an analogue to social-structural forgetting at the individual level. Availability refers to whether a memory may in principle be retrieved by the person, whilst accessibility denotes the degree of difficulty of retrieval at any given moment. For example, the person may have the personal knowledge that enables the construction of a memory for a specific event, but the lack of either immediate cues or mood congruency means it cannot be formulated right now, and is thus, for present purposes, 'forgotten'. Context here drives accessibility.

Active forgetting, in contrast to the simple erasure of the past, is concerned with accessibility rather than availability. The paradox of vital memories is that, much as it may be desirable to find ways in which they can be expunged, they become so intertwined with a sense of self that they must be retained. The problem is how to manage the ongoing relevance of these memories and to contain them, without attempting to deny their significance. Where we would depart from Conway is in treating accessibility as a purely cognitive matter. If memory is considered as a 
distributed system (Sutton, 2008; Sutton et al,, 2010), which encompasses both other people

(through direct and mediated interaction, such as social media) and material artefacts (i.e. diaries, photographs), then accessibility becomes a collective project. This is especially the case where we have responsibilities for the memories of others, such as in parent-child relationships. Here active forgetting - choosing to defer some aspect of a personal history for present purposes has to anticipate the needs of others in the future. For example, what adopted children are able to remember of their early years is dependent upon the decisions that adoptive parents and other carers have made regarding the preservation and updating of written personal histories of the child (known as 'lifestory books') and keeping artefacts such as toys or clothes which have travelled with the child (see Brown, Reavey and Brookfield, 2013). Adoptive parents face the dilemma of being responsible for keeping available details of the child's past which can be extremely difficult and distressing, on the grounds that in the future the child may need and have a justifiable right to know, whilst at the same time keeping these details as currently inaccessible.

\section{Ethics}

Discussions of the ethical and moral dimensions of remembering have been surprising limited in memory studies. Quite often this is seen as a matter that properly belongs to the purview of professional philosophers, with Avishai Margalit's The ethics of memory and Jeffrey Blustein's The moral demands of memory treated as key source texts. Despite the cogent and persuasive arguments presented in both texts, there are some difficulties with the approaches taken by both Margalit and Blumstein. Contemporary philosophy encourages a distinction between ethics and morality. This is particular acute in Margalit's work, who sees ethical questions, such as duties of care, as only relevant to the 'thick relations' constituted by families or communities, whilst moral obligations around what is right and wrong, are abstractions that apply to the 'thin relations' of nationhood or common humanity. This makes it difficult to apply evaluative criterion within a community of memory, since by Margalit's definition the presence of caring in thick relations means that they cannot be immoral (since caring is an unalloyed good). Both philosophers also offer highly normative treatments of ethics. For example, Blumstein formulates the conditions under which remembering a dead family member can become a moral imperative. But how does this imperative apply to a survivor of child sexual abuse remembering an abusive parent? Are they relieved of this imperative? If not, then at what cost to themselves do they choose to uphold it, and more importantly, what, for them, is the cost, both personally and socially, of not upholding the imperative?

The problem is with the imposition of unambiguous external moral standards and ethical goods to remembering rather than attempting to derive an ethics from the way that memory functions as part of the self-constitution of persons and collectives. Extending the previous example, we might say that at certain moments, the survivor might choose to actively forget his or her abusive parent to assert their autonomy. On other occasions, however, they might want to remember, but not honour, their parent because this affirms their place in broader family relationships. And on still further occasions, they may wish to both remember and partially honour the parent because they were, in the past, the source of love and care as well as abuse and harm. What criterion could we possibly apply to judge the ethical merits of the different decisions? It would be the extent to which the choice to remember or not remember enhances personal powers to act and expands the capacity to relate to and affectively engage with the others on each particular 
occasion. This criterion is developed from Spinoza's treatment of ethics (1677/1996), which has

been developed by political philosophers such as Gilles Deleuze (1988) and Antonio Negri (1991) and feminist philosophers such as Moira Gatens (1996) and Rosi Braidotti (2006). For a Spinozist ethics, there is no universal good or bad, only what is contingently good or bad for given persons engaged in a specific encounter with one other. Applied to vital memories, we would argue that ethical judgements of what we ought and ought not to remember must be radically specific to particular occasions and practices - that is to say, contexts - and be concerned with the question of what increases the vibrancy, capacities and modalities through which persons relate to each other as they jointly remember.

\section{Affect}

At the centre of Spinoza's ethics is affect. Over the past ten years there has been a huge renewed interest in emotion in the social sciences (see Greco and Stenner, 2008). The term affect is sometimes used as distinct from the patterned forms of felt evaluations that we call emotions to indicate a prior, relational and to some extent non-conscious engagement with the world. In Spinoza's philosophy, affect is the intensive, qualitative dimension of the encounter between bodies (see Brown and Stenner, 2001). For example, on entering a space such as a secure forensic health ward, one is immediate struck with a particular feeling that emerges from the ordering of bodies within that environment. This feeling is not immediately resolvable into a specific emotion, such as anxiety or anger, but nevertheless has a definite, phenomenological reality. Referring to affect as an 'intensive' rather than an 'extensive' property (e.g. as to akin temperature or pressure rather than distance or height), indicates that affect changes when it is divided through evaluation (see DeLanda, 2002). When we try to appraise what we are feeling, the outcome is an emotion that is qualitatively different from the affective relational form out of which it emerges. Affect might the be best thought of as an 'atmosphere' (Anderson, 2010) and crucially as involving time (here the convenient double meaning in French of 'le temps' as both 'the weather' and 'time' is helpful). Perhaps we can speak of there being 'affective climates' along with 'sites of memory', or even of the impossibility of thinking social memory apart from affect.

Thinking affect as an arrangement of relations, rather than purely an individual response, presents some challenges. For example, in previous work we have discussed how a CSA survivor recalls an incident from her childhood where she was abused by her brother (see Reavey \& Brown, 2009). A key element in the memory is of the brother locking the door to the room where the abuse subsequently occurred. We would argue that affect emerges here a relational, intensive property of the arrangement of the brother, the setting, the locked door. It is the arrangement of all these things together which gives the memory its affective charge. Each time the incident is recalled, the survivor is reconnected to that affective atmosphere, despite the physical and temporal distance. Despite its power, this affect is relatively undifferentiated, it does not initially deliver a clear meaning. But when the survivor focuses on the moment the door locked, everything changes. The locking of the door is a moment of qualification and subjectification of the affect. Focusing on that moment resolves the atmosphere into a discrete emotional experience (in this case, anger). Yet this need not necessarily be the case. Affect is non-deterministic. The survivor has had a wide range of emotional experiences around this recollection. This suggests that rationalizing one's emotional responses is unlikely to sufficient to 
manage this memory - what needs to be done is to explore ways of feeling a way through the atmosphere differently - to discovering new possibilities in what that atmosphere can offer.

\section{Space}

The idea that we are still connected to past affective atmospheres is difficult to entertain because of the way we think about space. Henri Bergson famously argued that our conceptual difficulties in approaching memory come from transposing a spatial framework to a process that is, by definition, temporal (1908/1991). We cannot think of memories as stored in a given site irrespective of whether that it the brain, the archive, or the group - because they are not entities with spatial properties (see Middleton and Brown, 2005; Burton, 2008). Nevertheless, remembering reconstructs events that can be clearly indexed to particular times and places (see Reavey, 2009; 2010), such as with recollections of the 2005 London Bombings. And place often appears to 'hold' our memories in a way that defines who we are, such that, as the folklorist Kent Ryden puts it 'we sense we are reaching the edge of our world when we run out of stories to tell about the places we see' (1993: 68). The challenge is to break with our usual perception of space as a container of experience and action. We must instead move towards a relational conception of space (see Massey, 2005; Thrift, 2008).

One means of doing this is through topological description (see Lury et al 2012). Topology is a branch of mathematics that is concerned with the effects of continuous transformation on relations between points. To do this, it conceives of space in terms of regions, edges and boundaries distributed across n-dimensional surfaces known as 'manifolds'. The questions asked of this space are not, primarily, to do with calculating the distance between points, but are instead are around the properties of the relations which are preserved as the space is deformed (thus very different spatial forms are considered as equivalent - homomorphic - if relations between points remain intact). The social psychologist Kurt Lewin (1936) argued that experience (or 'lifespace') ought to be understood as a manifold. In doing so, he was rejecting the idea of clear separation between the psychological subject and her or his external environment. Experience is constituted by the totality of actual and possible relations (for Lewin these are both physical and mental) that define us as part of the world. For example, we might be tempted to treat the experiences of forensic mental health patients on secure wards as bounded by the physical locked doors and walls of the institution. But patients are embedded in relationships that cross these apparent barriers through mediated means such as telephones, letters, photographs and music. The topological boundaries of the lifespace of the forensic mental health patient do not map on to the metric space of the ward - they are considerably broader and more spatially complex. In this way, we can begin to think that remembering must also follow these topological planes of connection which diverge considerably from our usual understanding of (Euclidean) space and (chronological) time.

\section{Institutional practices}

In her classic How institutions think, Mary Douglas demonstrated how the psychological (i.e. thinking, feeling, acting) was profoundly shaped by organizational and institutional contexts. Organizations such as large corporations, have their own logic and practices for preserving authorised versions of the past, in which staff then become inculcated (see Rowlinson et al, 
2010), even when that version of the past seems at odds with their own experiences (as in

Sennett's 1998 example of shared memories amongst redundant IBM workers). This raises the question of how institutions recruit or take hold of individual and collective modes of remembering. In pursuing this, it is worth noting the basic constraint identified by Luhmann (1995) in his systems theoretical approach. A given social system, such as the law, can only communicate through its own particular practices for synthesising information and extracting meaning. Were it to attempt to do otherwise, it would lose its identity as a system (Luhmann, 2008). When it comes to remembering, therefore, we would expect the legal system to demand that individual and collective memory delivers on matters such as evidence, accuracy, lack of ambiguity etc. However, institutions that are embedded in different social systems, such as medicine or art, will require very different things from memory. Therapy, for instance, asks for emotional significance, symbolic value, evidence of current patterns of thought and so on. We cannot then expect the law to communicate in anything other than a 'legal' manner, and for therapy to communicate in anything other than a 'therapeutic' manner. But is this is so, what happens when the law and therapy converge on a given memory problem - such as when person who recollects CSA seeks both legal and therapeutic redress?

Conway characterises the quality of autobiographical memory in the following way:

Memories can be wrong - sometimes very wrong. Memories can also be 'forgotten' for long periods of time and later remember with surprise. These are the facts of memory, they are not hypotheses or speculative beliefs ... But autobiographical memory (AM) also has other (redeeming) properties, two of which are that the representations of the past which the system creates are often basically accurate and the remember has some, limited, ability to assess memory accuracy. Volatility of access, errors, incompleteness, and even wholly false memories in the context of basic accuracy are the hallmarks of AM. (Conway, 1997: 150)

Once again, if we leave aside differences over whether autobiographical remembering is best considered as a purely personal or a distributed activity, there is little here that diverges from what feminist approaches, such as Janice Haaken (1998) and Sue Campbell (2003), would say about remembering CSA. However, these 'facts of memory' will show up in very different ways to the law and therapy, which have very different thresholds of tolerance for the sorts of metaphors, symbolisation and narrative structures in which CSA memories are typically framed (Campbell, 2003; Motzkau, 2009). This will inevitably create continuities and discontinuities in how remembering is treated, which all too often will be left to the survivor herself or himself to manage. We argue that when vital memories become the joint object of concern for several different institution practices, we need to acknowledge that the kinds of recollections that are produced in the different institutional contexts may appear to be contradictory and may not be readily synthesised. For example, in ongoing work we are finding that the way that police officers engage with witness statements from mental health service users differs considerably with how the same recollections would be handled in a therapeutic setting. We propose that what is needed in such cases is a formal recognition of the fact that what we can do with our memory and the forms our remembering takes is interdependent with institutional contexts; that the resulting contradictions across recollections ought not to be taken as undermining the credibility of the person concerned, and that this recognition be backed up with procedures for allowing 
institutional practices to jointly manage the divergences in remembered accounts that they

\section{Conclusion}

Our aim in this paper has been to explore the specific relationships between vital memories, as a subset of autobiographical memory, and a range of particular interactional contexts. We have argued that autobiographical memories of difficult and troubling events, especially those that involve violence, whether sexual or otherwise, are different in kind to other sorts of recollections. This does not mean that they fall so far outside the sphere of other kinds of experiences that they need to be theorised in a radically alternative way. On this basis, we have deliberately avoided using the language of trauma because it renders extraordinary what are, for those who experience them, the everyday commonplace difficulties of managing a distressing past. The ideas we have introduced - the interdependency of autobiographical memories; agency through ambivalence; forgetting as collectively managed accessibility; an ethics of remembering tied to self-constitution; affect as relational intensive property; the topological space of experience and the institutional co-construction of memories - are deliberately transdisciplinary in character. Rather than attempt to synthesise the commonsense of one discipline with another (say psychology with sociology), we have tried to think about what happens when the concepts of one discipline are transferred across contexts (e.g. what accessibility means for adoptive parents or how ethics applies to CSA survivors). In this sense context is a fundamental concern at every level of enquiry, from the interactional contexts in which remembering occurs, to the methodological contexts in which we engage with it, up to disciplinary contexts in which memory studies is worked. For us, it is the horizontal and vertical relationships that obtain between these multiple contexts which is of critical importance.

\section{References}

Allen MJ and Brown SD (2011) Embodiment and living memorial: The affective labour of remembering the 2005 London Bombings. Memory Studies 4(3): 312-327

Anderson B (2010) Affective atmospheres. Emotion, Space \& Society 2: 77-81

Bartlett FC (1932) Remembering: A study in experimental and social psychology. Cambridge: Cambridge University Press.

Bendien L (2012) Remembering (in) the past perfect: Ethical shifts in times. Memory Studies 5(4): 445-461.

Bendien L, Brown, SD and Reavey P (2010) Social remembering as an art of living: Analysis of a 'reminiscence museum'. In:, Schillmeier M and Domenech M (eds) New technologies and emerging spaces of care. London: Ashgate.

Bergson H (1913/2001) Time and free will. New York: Dover. 
Bernsten D and Rubin DC (2012) Understanding autobiographical memory: theories and approaches.

Cambridge: Cambridge University Press.

Blumstein, J (2008) The moral demands of memory. Cambridge: Cambridge University Press.

Braidotti, R (2006) Transpositions: On nomadic ethics. Cambridge: Polity.

Brookfield, H, Brown, SD and Reavey, P (2008) Vicarious and post-memory practices in adopting families: the re-production of the past through photography and narrative. Journal of Community and Applied Social Psychology 18: 474-491.

Brown, SD (2008) 'The quotation marks have a certain importance': Prospects for a 'memory studies. Memory Studies 1(3): 261-272.

Brown, SD and Reavey, P (2014) Vital Memories: Affect, Ethics and Agency. London: Routledge.

Brown, SD, Reavey, P and Brookfield, H (2012) Spectral object: Material links to difficult pasts for adoptive parents. In: Harvey, $\mathrm{P}$ et al Objects and materials: A Routledge companion. London: Routledge.

Burton, J (2008) Bergson's non-archival theory of memory. Memory Studies, 1(3): 321-340.

Campbell, S (2003) Relational Remembering: Retbinking the Memory Wars. Lanham: Rowman \& Littlefield Publishers.

Connerton, P (2008) Seven types of forgetting. Memory Studies 1: 59-72.

Connerton, P (2009) How modernity forgets. Cambridge: Cambridge University Press.

Conway, MA (1990) Autobiographical memory: an introduction. Buckingham: Open University Press.

Conway, MA and Jobson, L (2012) On the nature of autobiographical memory. In: Bernsten, D and Rubin, DC (eds) Understanding autobiographical memory: theories and approaches. Cambridge:

Cambridge University Press.

Conway, MA and Pleydell-Pearce, CW (2000) The construction of autobiographical memories in the self-memory system. Psychological Review 107: 261-288.

DeLanda, M (2002) Intensive science and virtual philosophy. London: Continuum.

Deleuze, G (1988) Spinoza: Practical philosophy. San Francisco: City Lights Books.

Draaisma, D (2000) Metaphors of memory: A history of ideas about the mind. Cambridge: Cambridge University Press.

Gatens, M (1996) Imaginary bodies: Ethics, power and corporeality. London: Routledge.

Greco, M and Stenner, P (2008) (eds) Emotions: A Social Science Reader. London: Routledge. 
Haaken, J and Reavey, P (eds) (2009) Memory Matters: Contexts for Understanding Recollections of Child

Sexual Abuse. London: Psychology Press/Routledge.

Haaken, J (1999) Heretical texts: The Courage to heal and the Incest Survivor Movement. In: Lamb. S (ed.) New versions of Victims: Feminists Struggle with the Concept. New York: New York University Press.

Haaken, J (1998) Pillars of Salt: Gender, Memory and the Perils of Looking Back. London: Free Association Press.

Lewin, K (1936) Principles of topological psychology. New York: McGraw Hill.

Lury, C, Parisi, L and Terranova, T (2012) Introduction: The becoming topological of culture. Theory, Culture \& Society 29(4/5): 3-35.

Margalit, A (2002) The ethics of memory. Cambridge, Mass: Harvard University Press.

Massey, D (2005) For space. London: Sage.

Matsuda, MK (1996) The memory of the modern. Oxford: Oxford University Press.

Middleton, D and Brown, SD (2005) The social psychology of experience: studies in remembering and forgetting. London: Sage.

Middleton, D and Edwards, D (1990) (eds) Collective Remembering. London: Sage.

Motzkau, J (2009) Speaking up against justice: suggestibility and children's memory on trial. In Haaken, J and Reavey, P (eds) Memory Matters: Contexts for Understanding Recollections of Child Sexual Abuse. London: Psychology Press/Routledge.

Negri, A (1991) The savage anomaly: The power of Spinoza's metaphysics and politics. Minneapolis: University of Minnesota Press.

O’Dell, L (2003) The 'harm' story in childhood sexual abuse: contested understandings, disputed knowledges. In: Reavey, P and Warner, S (eds) New feminist stories of child sexual abuse: sexual scripts and dangerous dialogues. London: Routledge.

Reavey, P (2003) When past meets present to produce a sexual 'other': Examining professional and everyday narratives of child sexual abuse and sexuality. In: Reavey, P \& Warner, S (eds) New feminist Stories of child sexual abuse: Sexual Scripts and Dangerous Dialogues. London: Routledge

Reavey, P (2009) The spaces of memory: rethinking agency through materiality. In: Haaken, J and Reavey, P (eds) Memory Matters: Contexts for Understanding Recollections of Child Sexual Abuse. London: Routledge.

Reavey, P (2010) Spatial markings: memory, narrative and survival. Memory Studies 3: 314-329.

Reavey, P \& Brown, SD (2006) Transforming agency and action in the past, into the present time: adult memories and child sexual abuse. Theory \& Psychology 16(2): 179-202. 
Reavey, P and Brown, SD (2010) The mediating role of objects in recollections of adult women survivors of child sexual abuse. Culture \& Psychology 15(4): 463-484.

Reavey, P and Warner S (eds) (2003) New Feminist Stories of Child Sexual Abuse: Sexual Scripts and Dangerous Dialogues. London: Routledge.

Ryden, KC (1993) Mapping the invisible landscape: Folkore, writing and the sense of place. Iowa City: University of Iowa Press.

Sennett, R (1998) Disturbing memories. In: Fara, P and Patterson, K (eds) Memory. Cambridge: Cambridge University Press.

Sturken, M (2008) Tourists of History: Memory, Kitsch, and Consumerism from Oklahoma City to Ground Zero. Durham: Duke University Press.

Sutton, J (2008). Between individual and collective memory: coordination, interaction, distribution. Social Research, 75(1), 23-48.

Sutton, J, Harris, C, Kell, P, \& Barnier, A (2010) The psychology of memory, extended cognition, and socially distributed remembering. Phenomenology and the Cognitive Sciences 9(4): $521-560$

Thrift, N (2008) Non-representational theory: Space, politics, affect. London: Routledge.

Wagoner, B (2014) 'Bartlett's theory of schema in reconstruction', Theory \& Psychology, forthcoming.

Weinrich, H (2004) Lethe: The art and critique of forgetting. Cornell University Press.

Yates, FA (1966) The art of memory. London: Routledge.

Young, A (1995) The harmony of illusions: Inventing Post-Traumatic Stress Disorder. Princeton:

Princeton University Press. 